\title{
The use of equivalent annual cost for cost-benefit analyses in flood risk reduction strategies
}

\author{
M.A. (Maarten) Schoemaker ${ }^{1}$, J.G. (Jules) Verlaan ${ }^{1}$, R. (Robert) Vos ${ }^{2}$, M. (Matthijs) Kok ${ }^{1}$ \\ ${ }^{1}$ Delft University of Technology, faculty of civil engineering, Stevinweg 1, $2628 \mathrm{CN}$, Delft, the Netherlands \\ ${ }^{2}$ Rijkswaterstaat, Ministry of Infrastructure \& Environment, Zuiderwagenplein 2, 8224 AD, Lelystad, the Netherlands
}

\begin{abstract}
In many parts of the world, flooding is a big risk. There are numerous strategies to reduce flood risk. The amount of flood risk reduction strategies grows exponentially with the amount of possible measures that can be implemented and possible timings when measures can be implemented. In this paper, the use of a financial method called "equivalent annual cost" (EAC) is assessed to reduce that number of strategies and evaluate cost-optimal strategies. The use of EAC allows the comparison between short-term and long-term measures by expressing them into an annual interest weighted expected expenditure. As soon as a measure has to be implemented (i.e. the annual risk becomes too large or the safety standards are exceeded), the EAC for all combinations of measures is determined and the combination is implemented with the lowest EAC. This almost leads to cost-optimal flood risk reduction strategies that, by manual optimization, can be improved further. A case study has also been performed in the Hollandsche IJssel which proved the use of EAC. Here it has led to cost-optimal flood risk reduction strategies. The method is tested in one case and it is recommended to apply and test it in other cases as well.
\end{abstract}

\section{Introduction}

\subsection{The economic approach}

The goal of flood risk management in the Netherlands is to minimize the present value (PV) of risk and investments. In the cost-benefit analysis (CBA), because of discounting the postponement of an investment leads to a reduction of the PV of investments while it also leads to an increase of PV of risk. For some implementation timing of the investment, the sum of PV of risk and investments is minimal.

As combinations of measures can be implemented at a variety of implementation timings, for complex situations this leads to billions of possible flood risk reduction strategies. In this paper, the use of equivalent annual cost (EAC) is assessed to reduce the amount of combinations and assess cost-optimal flood risk reduction strategies more easily for within the cost-benefit analysis.

Currently in the Netherlands, new safety standards are implemented that lead to reinforcements of dikes. A possible rule is that as soon as the flood probability is exceeded, the dike section is reinforced. Especially for more complex situations, such as when the interaction with a storm surge barrier is part of the system (see section 4), this may not necessarily be optimal. The use of EAC combined with brute force may provide a solution for such cases as is demonstrated in this paper.
Besides economic aspects other damages and profits can be addressed in an integral approach as well. These are for instance related to nature, shipping, flooding of unembanked areas, historical value or the flexibility of a strategy. This paper focusses on the economic aspects. However, other aspects could be taken into account by expressing them in monetary terms.

The methods elaborated in this paper can be used for flood risk reduction in general. Any kind of measure that reduces flood risk can be assessed. This includes (i.e.) dike reinforcements, damage reduction measures (such as elevated housing), evacuation, spatial reorganization or the reduction of high water levels by the construction of a storm surge barrier (as the case study in chapter 4 will show). The only requirement is that it can be expressed in monetary terms.

\subsection{Amount of independent combinations}

To properly identify the problem with brute force determining flood risk reduction strategies assuming any possible measure can be implemented at any possible time, consider the following situation:

- Three dike sections: $\mathrm{a}, \mathrm{b}$ and $\mathrm{c}$.

- One possible dike reinforcement per section

- Possible implementation years: 2020, 2025 or 2030.

a Corresponding author: maschoemaker@gmail.com 
How many possible flood risk reduction strategies are there without using safety standards of any sort? In the year 2020, we can either:

1) Reinforce nothing

2) Reinforce one section: $\mathrm{a}, \mathrm{b}$ or $\mathrm{c}$

3) Reinforce two sections: a \& b or a \& c or b \& c

4) Reinforce all three sections: a, b \& c

In total there are 8 combinations possible in the year 2020. This can also be denoted by the following equation:

$$
N_{\text {combinations }}=\sum_{k=0}^{n}\left(\begin{array}{l}
n \\
k
\end{array}\right)=2^{n}=8
$$

Where $n$ is the amount of independent measures, in this case the three dike sections. Implementation of one of the 8 combinations each branch out into several possibilities for 2025. Depending on the decision made in 2020, the following combinations are possible:

1) If nothing is reinforced, the same 8 possible combinations remain in 2025 .

2) If one section is reinforced, only the two remaining sections can be reinforced (or not), resulting in $2^{2}=4$ remaining combinations.

3) If two sections are reinforced, only the one remaining section can be reinforced (or not), which leaves 2 combinations

4) If all three sections are reinforced, then only nothing can be done (1 combination).

The total amount of possible combinations therefore increases to:

$$
N_{\text {strategies }}=\sum_{k=0}^{n}\left(\begin{array}{l}
n \\
k
\end{array}\right) \cdot 2^{n-k}=3^{n}=27
$$

The same thing can be said about the year 2030, which then leads to:

$$
N_{\text {strategies }}=\sum_{k=0}^{n}\left(\begin{array}{l}
n \\
k
\end{array}\right) \cdot 3^{n-k}=4^{n}=64
$$

This means the total amount of possible flood risk reduction strategies $N$ in general is equal to the following:

$$
N_{\text {strategies }}=(1+\tau)^{n}
$$

Where $n$ is the amount of possible independent measures that can be implemented and $\tau$ is the amount of possible implementation timings. Independence in this situation means that if a measure has been implemented, all other measures can still be implemented.

As in every possible implementation timing the flood risk has to be determined, the total amount of times the flood risk has to be computed is therefore equal to:

$$
N_{\text {computations }}=\sum_{\tau=1}^{\tau}(1+\tau)^{n}=\tau(1+\tau)^{n}
$$

As can be seen the amount of combinations increases rapidly. For example: suppose there are 8 dike sections and they can be reinforced once every year between 2016 and 2050. The total amount of possible flood risk reduction strategies then equals approximately $2.82 * 10^{12}$. Of this however, only one is cost-optimal. To determine this, this means flood risk has to be computed $9.87 * 10^{13}$ times if all possible flood risk reduction strategies have to be evaluated to find the cost-optimal strategy.

\subsection{Amount of dependent combinations}

In practice the amount of possible combinations lies even much higher. Take for instance dike reinforcements: assumed in section 1.2 is that there is only one possible measure that can be implemented per dike section. This makes all measures independent of one another resulting in equation (4).

In practice, this is not the case. For instance, the dike can be increased in height by $0.1 \mathrm{~m}$ or $0.5 \mathrm{~m}$ or $1.0 \mathrm{~m}$ or any other number. Also, suppose the dike height equals $2.0 \mathrm{~m}$. If the dike has been increased in height to $3.0 \mathrm{~m}$, then increasing the height to $2.5 \mathrm{~m}$ would no longer be possible, meaning there is no independence between these measures.

The amount of possible combinations can then also be computed. Suppose there are two dike sections with for each dike section two possible dike reinforcements. This will be denoted as two sets of measures (the two dike sections) and two variants within both of these sets (the two reinforcements). The amount of combinations at the first implementation timing then equals:

$$
N_{\text {combinations }}=2^{n} \cdot \prod_{k=1}^{n}\left(\frac{m_{k}+1}{2}\right)
$$

Where $m_{k}$ represents the amount of variants per $\mathrm{k}$-th set. Filling in this equation will result in 9 possible combinations in the first year. Taking into account multiple years, no evident equation was found as the problem proved to be too complex as it branches out in too many possibilities. By hand it was shown that this increased to 36 strategies for two implementation timings and 100 strategies for three implementation timings.

\section{Equivalent Annual Cost}

\subsection{Definition}

This section will introduce the concept of equivalent annual cost (EAC). As found in [1] by definition, the EAC is an annual cash flow that if made every year for the duration of the project, the discounted summation will lead to the net present value (NPV) of a project, hence assuming discrete compounding: 


$$
N P V=\sum_{t=1}^{t^{*}} \frac{E A C}{(1+i)^{t}}
$$

Where $i$ is the interest rate, $t$ is the time and $t^{*}$ is the total duration of the project. Rewriting this equation, the EAC can be derived:

$$
\begin{gathered}
E A C=\frac{N P V}{A_{t^{*}, i}} \\
A_{t^{*}, i}=\sum_{t=1}^{t^{*}} \frac{1}{(1+i)^{t}}=\frac{1-(1+i)^{-t^{*}}}{i}
\end{gathered}
$$

Where $A_{t^{*}, i}$ is called the annuity factor, which is the sum of all discount factors for the duration of the project.

The equivalent annual cost is often used to determine optimal replacement cycles as the following example will demonstrate.

A certain business owner can buy a machine and choose to replace it every 2 years or every 4 years. The purchase value of the machine is 10,000 euros, while the annual maintenance starts at 2000 per year and increases by 200 euros per year for each year after that. The residual value after 2 years is 9000 euros and after 4 years is 8200 euros. The discrete discount rate is $5 \%$.

When a replacement cycle of 2 years is selected, the cash flows that occur are displayed in table 1.

\begin{tabular}{|l|r|r|r|}
\hline Year & $\mathbf{0}$ & $\mathbf{1}$ & $\mathbf{2}$ \\
\hline Initial costs & $-10,000$ & & \\
\hline Maintenance & & -2000 & -2200 \\
\hline Residual value & & & 9000 \\
\hline Cash flow & $-10,000$ & -2000 & 6800 \\
\hline Present value & $-10,000$ & -1905 & 6168 \\
\hline
\end{tabular}

Table 1. Costs for a replacement cycle of 2 years with a discount rate of $5 \%$

Summarizing all present values, the obtained net present value (NPV) is -5737 euros.

When a replacement cycle of 4 years is selected, the cash flows that occur are displayed in table 2.

\begin{tabular}{|l|r|r|r|r|r|}
\hline Year & $\mathbf{0}$ & $\mathbf{1}$ & $\mathbf{2}$ & $\mathbf{3}$ & $\mathbf{4}$ \\
\hline Initial costs & $-10,000$ & & & & \\
\hline $\begin{array}{l}\text { Main- } \\
\text { tenance }\end{array}$ & & -2000 & -2200 & -2400 & -2600 \\
\hline $\begin{array}{l}\text { Residual } \\
\text { value }\end{array}$ & & & & & 8200 \\
\hline CF & $-10,000$ & -2000 & -2200 & -2400 & 5600 \\
\hline$P V$ & $-10,000$ & -1905 & -1995 & -2073 & 4607 \\
\hline
\end{tabular}

Table 2. Costs for a replacement cycle of 4 years with a discount rate of $5 \%$

The NPV for a replacement cycle of 4 years equals 11366 euros. By dividing the NPV with the annuity, the equivalent annual cost (EAC) can be determined for these replacement cycles, see equation (8). 2-year replacement cycle:

$$
\begin{aligned}
& A_{2,0.04}=\frac{1-(1+i)^{-t^{*}}}{i}=\frac{1-(1+0.05)^{-2}}{0.05}=1.859 \\
& E A C=\frac{N P V}{A_{t, r}}=\frac{-5737}{1.859}=-3085
\end{aligned}
$$

4-year replacement cycle:

$$
\begin{aligned}
& A_{2,0.04}=\frac{1-(1+i)^{-t^{*}}}{i}=\frac{1-(1+0.05)^{-2}}{0.05}=3.546 \\
& E A C=\frac{N P V}{A_{t, r}}=\frac{-11366}{3.546}=-3205
\end{aligned}
$$

The EAC of replacing the machine every 2 years is lower than the EAC of replacing the machine every 4 years. This means replacing the machine every 2 years is economically optimal.

The resulting EAC can be checked, as the sum of the present values of the equivalent annual cost for each year should result in the NPV of the project:

\begin{tabular}{|l|r|r|r|r|}
\hline Year & $\mathbf{0}$ & $\mathbf{1}$ & $\mathbf{2}$ & $\boldsymbol{N P V}$ \\
\hline CF & $-10,000$ & -2000 & 6800 & \\
\hline PV $(\mathrm{CF})$ & $-10,000$ & -1905 & 6168 & -5737 \\
\hline EAC & & -3085 & -3085 & \\
\hline PV(EAC) & & -2938 & -2799 & -5737 \\
\hline
\end{tabular}

Table 3. Costs PV for 2-year replacement cycle

\begin{tabular}{|l|r|r|r|r|r|r|}
\hline Year & $\mathbf{0}$ & $\mathbf{1}$ & $\mathbf{2}$ & $\mathbf{3}$ & $\mathbf{4}$ & $\boldsymbol{P V}$ \\
\hline $\mathrm{CF}$ & $-10,000$ & -2000 & -2200 & -2400 & 5600 & \\
\hline $\mathrm{PV}(\mathrm{CF})$ & $-10,000$ & -1905 & -1995 & -2073 & 4607 & $-11,366$ \\
\hline EAC & & -3205 & -3205 & -3205 & -3205 & \\
\hline PV(EAC) & & -3053 & -2907 & -2769 & -2637 & $-11,366$ \\
\hline
\end{tabular}

Table 4. Costs PV for 4-year replacement cycle

The method seems to be widely used in other fields of engineering and was first introduced in 1923 [2]. The reason that it could also work in flood risk is because it can compare short-term and long-term measures with each other, by expressing them in an annual value.

\subsection{Application in flood risk}

The goal in flood risk is to find the flood risk reduction strategy where the present value of risk and investments is minimal taking into account minimal societal costs as well. The EAC method can be used as means to determine cost-optimal strategies. As soon as a measure has to be implemented, an investment can be made that reduces flood risk. After implementation, the flood probability will decrease immediately, but over time will increase again due to (i.e.) subsidence and sea level rise. The same goes for the annual flood risk, which also includes economic growth. 
More expensive measures are likely to cause more risk reduction in comparison with cheaper measures. This means their investment is relatively high, but the total flood risk after implementation is lower. This is therefore a longer-term investment in comparison with cheaper measures. The EAC can compare these measures with each other by means of the following procedure.

The annual risk after implementation can be discounted to achieve the discounted annual flood risk (DAFR). For each timeframe $t^{*}$ after implementation, from 1 year to 100 years, the PV of the investment and risk can be determined by summarizing the investments with the risk from year 1 to the timeframe $t^{*}$. In terms of an equation:

$$
P V\left(t^{*}\right)=I+\sum_{t=1}^{t=t^{*}} \operatorname{DAFR}(t)
$$

By dividing the PV with the annuity for the same timeframe $t^{*}$, the EAC as a function of the timeframe $t^{*}$ can be determined. The timeframe where the EAC is at a minimum is the optimal economical lifespan. This is displayed in figure 1 .

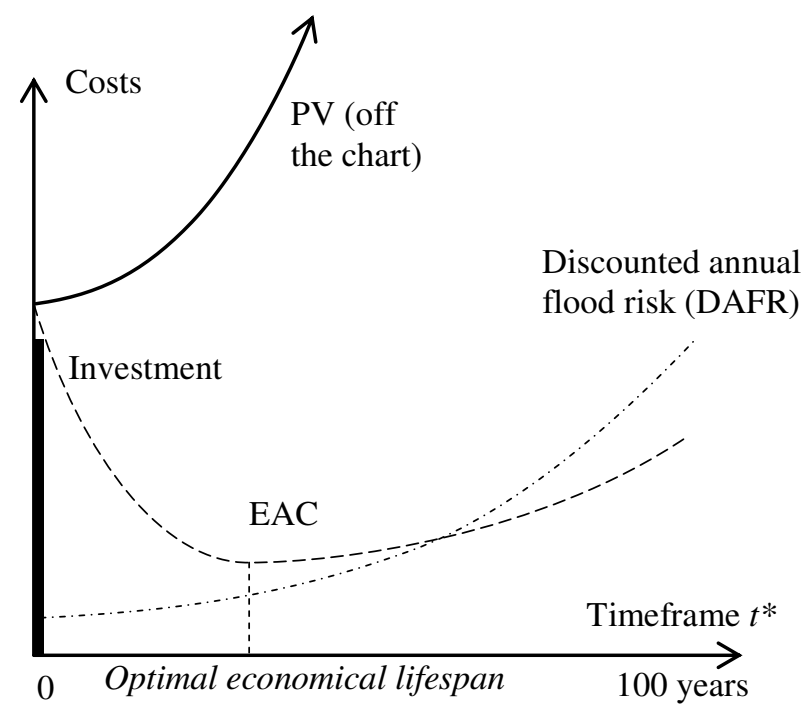

Figure 1. Determination of optimal economical lifespan using the EAC

By determining the optimal economical lifespan for every combination of investments and thus the minimum EAC for every combination of measures, short-term and long-term combinations can be compared with each other. The combination of measures with the lowest equivalent annual cost is then the cost-optimal combination. This is the combination of measures that should be implemented.

The principle of determining the lowest $\mathrm{PV}$ of investments and flood risk using the EAC method is to keep the EAC as low as possible at all times, which in terms of an equation can be denoted as follows:

$$
\begin{aligned}
& \text { for } t=\text { year }_{i} . . \text { year }_{n}: \\
& \min (E A C[\text { comb }, t])
\end{aligned}
$$

Where comb stands for the combination with the lowest equivalent annual cost, which includes the option to do nothing and accept another year of risk. Using continuous discounting instead of discrete discounting (as the EAC is a continuous function), the EAC for one year of risk is equal to the flood risk discounted for one year:

$$
\begin{aligned}
& E A C[R(t)]=\frac{P V\left[R\left(t^{*}=1\right)\right]}{A_{1, i}} \\
& =P V[R(1)]=R(t) \cdot e^{-i}
\end{aligned}
$$

This means that a combination of measures is implemented as soon as the EAC of the optimal combination of measures is lower than the annual flood risk. In terms of an equation:

$$
t_{i m p l} \rightarrow R_{t_{i m p l}} \cdot e^{-i}=E A C\left[\operatorname{comb}, t_{i m p l}\right]
$$

This would reduce the amount of required computations. Given the situation described as in section 1.2 , the amount of computations would be reduced from equation (5) to an upper boundary of equation (14) (assuming no measures are implemented at all meaning every combination has to be checked at any time).

$$
\begin{aligned}
& N_{\text {computations }}=\tau(1+\tau)^{n} \\
& N_{\text {computations }}=2^{n} \cdot \tau \cdot \tau *
\end{aligned}
$$

Where $\tau^{*}$ are the amount of economical lifespans for which the flood risk is evaluated (after fictive implementation of any combination of measures as described by figure 1). In the example of section 1.2 the amount of computations to find the cost-optimal flood risk reduction strategy is reduced from $9.87 * 10^{13}$ to 89,600 assuming the flood risk is determined for 10 economical lifespans.

It would also be possible to use safety standards. In that case, as soon as the flood probability exceeds the safety standards, the minimal EAC for all combinations of measures is determined. The combination with the lowest EAC is then implemented. No comparison is made with the current flood risk.

For more information about the implementation of EAC in flood risk, see [7].

\subsection{Theoretical example with one permanent measure}

A small example is elaborated where there is only one measure available that permanently reduces the flood risk to zero, so after implementation $R(t)=0$. Suppose the flood risk as function of time until that measure is implemented can be described by the following equation:

$$
R(t)=R_{0} \cdot e^{(g+h) \cdot t}
$$


Where $R(t)$ is the flood risk as function of time, $R_{0}$ is the flood risk at time $t=0, g$ equals the annual economic growth and $h$ equals the annual risk increase due to increase in water level relative to the crest height (subsidence and sea level rise).

The goal is to find the optimal implementation timing $t_{\text {impl }}$ using the EAC. According to equation (12), the annual flood risk is equal to the equivalent annual cost for 1 year of flood risk, discounted for one year. This means at time $t_{i m p l}$, the equivalent annual cost for the flood risk equals:

$$
\operatorname{EAC}\left[R\left(t_{\text {impl }}\right)\right]=R_{0} \cdot e^{(g+h) \cdot t_{i m p l}+i}
$$

According to equation (13), as soon as the EAC of implementing the measure becomes smaller than the EAC of risk, the measure should be implemented. The cost for this measure equals $C$. Because the risk after implementation is zero, the optimal economical lifespan is infinite (investment costs are spread out over an infinite time horizon as the measure permanently solves the flood risk problem), hence $t^{*}=\infty$. This means the EAC for implementing this measure is minimal for:

$$
E A C[I]=\frac{C}{A_{\infty}}=\frac{C \cdot i}{e^{-i}}
$$

At the optimal implementation, the equivalent annual cost of the risk equals the equivalent annual cost of the measure as implied by equation (13). Using that, the optimal implementation timing can be determined.

$$
\begin{gathered}
E A C\left[R\left(t_{\text {impl }}\right)\right]=E A C[I] \\
\Rightarrow R_{0} \cdot e^{(g+h) \cdot t_{\text {impl }}+i}=\frac{C \cdot i}{e^{-i}} \\
t_{\text {impl }}=\frac{\ln \left(\frac{C \cdot i}{R_{0}}\right)}{g+h}
\end{gathered}
$$

\section{Comparison with minimizing PV}

\subsection{Theoretical example with one permanent measure}

A comparison can be made between minimizing the present value and using the equivalent annual cost for simpler cases. Suppose the same situation as section 2.3. The only variable in that situation is the implementation timing $t^{*}$. The discounted annual risk as function of time can be denoted:

$$
\operatorname{DAFR}(t)=R(t) \cdot e^{-i t}=R_{0} \cdot e^{(g+h-i) \cdot t}
$$

Which means the present value of risk for the entire lifespan until the implementation timing can be denoted by integrating equation (20).

$$
\begin{aligned}
& P V\left[R\left(t_{i m p l}\right)\right]=\int_{t=0}^{t=t_{\text {impl }}} D A F R(t) d t \\
& =\frac{R_{0}\left(e^{(g+h-i) \cdot t_{\text {impl }}}-1\right)}{g+h-i}
\end{aligned}
$$

The present value of risk shows similarities with the Gordon growth model as the PV of risk grows at a constant rate in perpetuity. The present value of investments simply consists of the costs multiplied with the discount factor at the optimal implementation timing:

$$
P V\left[I\left(t_{\text {impl }}\right)\right]=C \cdot e^{-i \cdot t_{i m p l}}
$$

The goal is to minimize the sum of risk and investments.

$$
\begin{aligned}
& \min \left\{P V\left[R\left(t_{\text {impl }}\right)\right]+P V\left[I\left(t_{\text {impl }}\right)\right]\right\} \\
& =\min \left\{\frac{R_{0}\left(e^{(g+h-i) \cdot t_{\text {impl }}}-1\right)}{g+h-i}+C \cdot e^{-i \cdot t_{\text {impl }}}\right\}
\end{aligned}
$$

With the only variable being the implementation timing $t_{i m p l}$, the implementation timing can be determined by taking the derivative to $t_{i m p l}$ and solving for zero:

$$
\begin{aligned}
& \min \left\{P V\left[R\left(t_{\text {impl }}\right)\right]+P V\left[I\left(t_{\text {impl }}\right)\right]\right\} \\
& \Rightarrow \frac{d\left\{P V\left[R\left(t_{\text {impl }}\right)\right]+P V\left[I\left(t_{\text {impl }}\right)\right]\right\}}{d t_{\text {impl }}}=0
\end{aligned}
$$

This results in the optimal implementation timing:

$$
t_{\text {impl }}=\frac{\ln \left(\frac{C \cdot i}{R_{0}}\right)}{g+h}
$$

As can be seen, using the EAC annual cost will result in the same implementation timing as minimizing the PV of risk and investments in this situation.

\subsection{Theoretical example with multiple measures in fixed implementation order}

This example elaborates whether or not for more complex situations using the EAC method will also result in the same strategy as minimizing the PV of risk and investments.

Suppose that as in section 2.3 and 3.1 the annual flood risk can be denoted by equation (15). In this situation 
however, multiple measures are allowed, a total of $n$ measures. They are only allowed in a fixed order and have a fixed influence on the flood risk denoted by the following equation directly after implementing the measure:

$$
R_{\text {after }}(t)=R_{\text {before }}(t) \cdot e^{-R F_{k}}
$$

Where $R F_{k}$ represents a reduction factor for the $\mathrm{k}$-th measure. Suppose the last $n$-th measure reduces the flood risk to zero just as in section 2.3 and 3.1. For other measures $R F_{k}>0$. A graphical representation of equation (25) is displayed in figure 2.

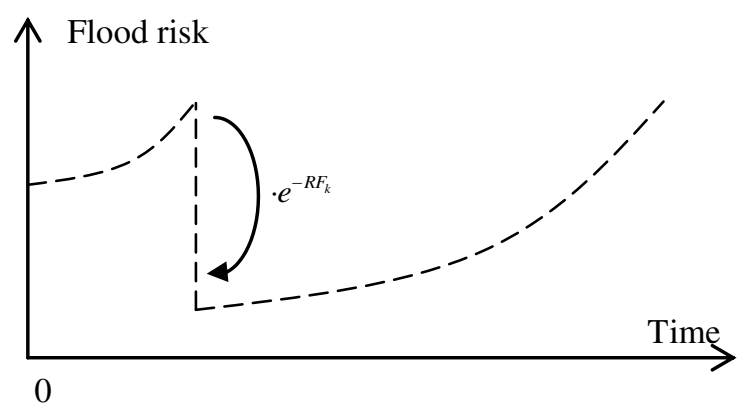

Figure 2. Reduction of flood risk as a result of the implementation of a measure

\subsubsection{Minimizing PV}

The total present value of risk for the situation described in the section 3.2 can be determined for every $\mathrm{k}$-th implementation timing $t_{i m p l, k}$. Results are displayed in the following equation:

$$
\begin{aligned}
& P V[R]=\int_{t=0}^{t=t_{\text {impl }, 1}} R_{0} \cdot e^{(g+h-i) \cdot t} d t \\
& +\int_{t=t_{\text {inpl }, 1}}^{t=t_{\text {inpl }, 2}} R_{0} \cdot e^{(g+h-i) \cdot t-R F_{1}} d t \\
& +\ldots+\int_{t=t_{\text {inpl }, n-1}}^{t=t_{\text {timpl }, n}} R_{0} \cdot e^{(g+h-i) \cdot t-\sum_{j=1}^{n} R F_{j-1}} d t \\
& =\sum_{k=1}^{n} \frac{R_{0} \cdot\left(e^{(g+h-i) \cdot t_{\text {impl }, k}}-e^{(g+h-i) \cdot t_{\text {timpl }, k-1}}\right) \cdot e^{-\sum_{j=1}^{k} R F_{j-1}}}{g+h-i}
\end{aligned}
$$

Where $R F_{0}$ is a dummy variable equal to zero (risk reduction at time $t=0)$. Again, the present value of risk shows similarities with the Gordon growth model.

The present value of investments is simply the sum of all discounted investments.

$$
P V[I]=\sum_{k=1}^{n} C_{k} \cdot e^{-i \cdot t_{\text {impl }, k}}
$$

Summarizing the PV of investment and risks, the total present value is derived. The total PV can be minimized by determining the derivative for every $t_{i m p l, k}$ and solving for the derivative being zero, see also equation (24). This results in n-equations with n-variables (the implementation timings). After solving, the following equations can be derived:

$$
\begin{gathered}
\text { for } k=1 . . n-1: \\
t_{i m p l, k}=\frac{\ln \left(\frac{C_{1} \cdot i}{R_{0} \cdot\left(e^{R F_{k}}-1\right)}\right)+\sum_{j=1}^{k} R F_{j}}{g+h} \\
t_{\text {impl }, n}=\frac{\ln \left(\frac{C_{n} \cdot i}{R_{0}}\right)+\sum_{j=1}^{k} R F_{j-1}}{g+h}
\end{gathered}
$$

Interestingly, the implementation timing of the last measure, equation (29), is comparable with the implementation timing of equation (19) with the addition of the total risk reduction applied previously.

\subsubsection{Using the EAC method}

To determine the implementation timings $t_{i m p l, k}$ using the EAC method results in the necessity to determine the optimal economical lifespan whenever a measure has to be implemented. As can be seen in figure 1 at the optimal economical lifespan, the derivative of the EAC to the economical lifespan equals zero, in other words:

$$
\frac{d E A C\left[I_{k}\right]}{d t^{*}{ }_{k}}=0
$$

Where $t^{*}{ }_{k}$ denotes the economical lifespan for the $\mathrm{k}$ th measure. To determine the EAC of the investment using equation (8), the present value of the investment has to be determined. The PV of the investment is equal to the magnitude of the investment (without discounting, this is not required because this is ultimately evened out) plus the addition of the total risk as function of the economical lifespan. This is similar to the integration sections of equation (26). The resulting PV of investments is displayed in equation (31) while the annuity for each economical lifespan is displayed in equation (32).

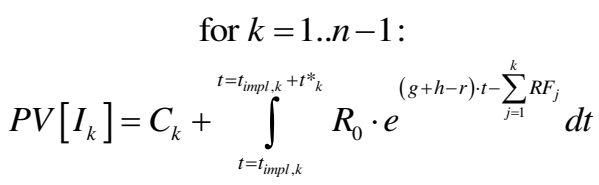

$$
\begin{aligned}
& A_{t^{*}, i}=\frac{e^{-i} \cdot e^{-i \cdot t^{*}{ }_{k}}}{i}
\end{aligned}
$$

This means the EAC of implementing a measure for the k-th investment can be elaborated by the use of the following equation: 


$$
E A C\left[I_{k}\right]=\frac{i \cdot\left(C_{k}+\int_{t=t_{\text {inpl }, k}}^{\text {for } k=1 . . n-1:} R_{0} \cdot e^{(g+h-r) \cdot t-\sum_{j=1}^{k} R F_{j}} d t\right)}{e^{-i} \cdot e^{-i \cdot t^{*} k_{k}}, k+t^{*}{ }_{k}}
$$

For the $\mathrm{n}$-th measure, the risk after implementation is zero, thus the optimal economical lifespan is infinite, which means here equation (17) is valid (with $C$ replaced by $C_{n}$ ).

At the optimal implementation timing, the EAC of implementing a measure $E A C\left[I_{k}\right]$ should equal the EAC of annual risk $E A C\left[R\left(t_{i m p l, k}\right)\right]$ as implied by equation (13), meaning:

$$
\begin{gathered}
\text { for } k=1 . . n: \\
E A C\left[R\left(t_{i m p l, k}\right)\right]=E A C\left[I_{k}\right]
\end{gathered}
$$

The EAC of annual risk $E A C\left[R\left(t_{i m p l, k}\right)\right]$ can be determined by combining equation (16) with the addition of the risk reduction factors:

$$
\begin{gathered}
\text { for } k=1 . . n: \\
E A C\left[R\left(t_{i m p l, k}\right)\right]=R_{0} \cdot e^{(g+h) \cdot t_{i m p l, k}+i-\sum_{j=1}^{k} R F_{j-1}}
\end{gathered}
$$

Where $R F_{0}$ is a dummy variable equal to zero (risk reduction at time $t=0)$. There are now 2 n- 1 equations when applying equations (30) and (34). No analytical solution was found, except for the $n$-th measure:

$$
t_{i m p l, n}=\frac{\ln \left(\frac{C_{n} \cdot i}{R_{0}}\right)+\sum_{j=1}^{k} R F_{j-1}}{g+h}
$$

This proves that the last implementation timing for using the EAC method is the same as for using the minimizing PV method. For other implementations, the implementation timings can be computed numerically.

\subsection{Numerical example for comparison}

This section shall numerically elaborate the difference between minimizing the PV of investments and risk and using the EAC method for two simplified situations using the methods described in section 3.2.

\subsubsection{Two equal measures}

Suppose there are two measures with equal influence and a third measure that permanently reduces the flood risk to zero. They must all be implemented and can only be implemented in a fixed order. Suppose the following parameters:

$$
\begin{aligned}
& R_{0}=10^{6}, g=0.02, h=0.06, \mathrm{i}=0.025 \\
& R F_{1}=4, R F_{2}=4 \\
& C_{1}=400 \cdot 10^{6}, C_{2}=400 \cdot 10^{6} C_{2}=1000 \cdot 10^{6}
\end{aligned}
$$

Using these input parameters, a comparison of implementation timings can be made between minimizing the PV of investments and risk from section 3.2.1 and using the EAC method from section 3.2.2. Results are displayed in table 5 and graphically in figure 3.

\begin{tabular}{|c|r|r|r|}
\hline & PV & EAC & Difference \\
\hline$t_{\text {impl }, 1}[\mathrm{yr}]$ & 29.01 & 33.65 & +4.64 \\
\hline$t_{\text {impl }, 2}$ [yr] & 79.01 & 81.93 & +2.92 \\
\hline$t_{\text {impl }, 3}$ [yr] & 140.24 & 140.24 & 0 \\
\hline PV [euro] & $387.88 \cdot 10^{6}$ & $392.74 \cdot 10^{6}$ & $+1.25 \%$ \\
\hline
\end{tabular}

Table 5. Implementation timings and PV for both methods

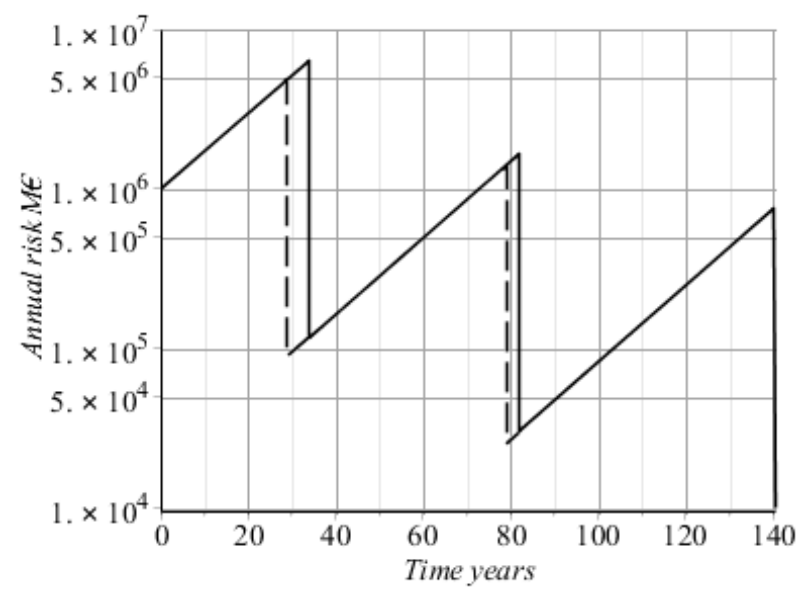

Figure 3. Comparing the use of minimizing PV (dashed line) and using EAC (solid line) for two equal measures

It can be concluded that the present value of risk and investments using the EAC method is increased slightly. More important though is that the use of EAC implies delayed implementation timings, especially in the relative short term future. As expected, the implementation timing for the last measure that permanently reduces flood risk is equal for both methods.

\subsubsection{Four unequal measures}

Suppose there are four measures with unequal influence and a fifth measure that permanently reduces the flood risk to zero. They must all be implemented and can only be implemented in a fixed order. Suppose the following parameters:

$$
\begin{aligned}
& R_{0}=10^{6}, g=0.02, h=0.06, \mathrm{i}=0.025 \\
& R F_{1}=1, R F_{2}=2, R F_{3}=5, R F_{4}=3 \\
& C_{1}=50 \cdot 10^{6}, C_{2}=100 \cdot 10^{6}, C_{3}=500 \cdot 10^{6} \\
& C_{4}=200 \cdot 10^{6}, C_{5}=1000 \cdot 10^{6}
\end{aligned}
$$


Using these input parameters, a comparison of implementation timings can be made between minimizing the PV of investments and risk from section 3.2.1 and using the EAC method from section 3.2.2. Results are displayed in table 6 and graphically in figure 4.

\begin{tabular}{|r|r|r|r|}
\hline & PV & EAC & Difference \\
\hline$t_{\text {impl }, 1}[\mathrm{yr}]$ & 8.52 & 23.44 & +14.92 \\
\hline$t_{i m p l, 2}[\mathrm{yr}]$ & 25.77 & 34.74 & +8.97 \\
\hline$t_{i m p l, 3}[\mathrm{yr}]$ & 69.16 & 71.51 & +2.35 \\
\hline$t_{i m p l, 4}[\mathrm{yr}]$ & 120.76 & 123.23 & +2.47 \\
\hline$t_{i m p l, 5}[\mathrm{yr}]$ & 206.52 & 206.52 & 0 \\
\hline PV [euro] & $343.52 \cdot 10^{6}$ & $359.53 \cdot 10^{6}$ & $+4.66 \%$ \\
\hline
\end{tabular}

Table 6. Implementation timings and PV for both methods

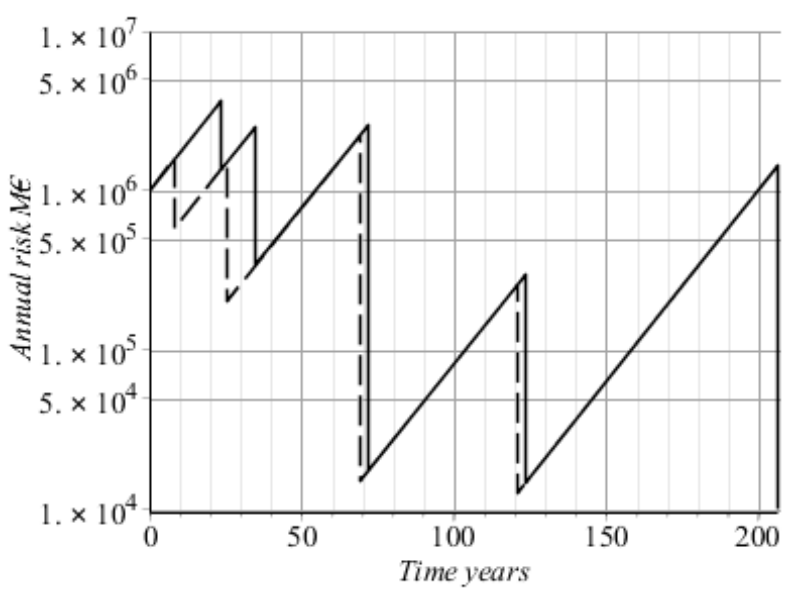

Figure 4. Comparing the use of minimizing PV (dashed line) and using EAC (solid line) for four unequal measures

The same conclusion can be drawn: the present value of risk and investments is only increased slightly, while mostly short-term investments are delayed, in this case even significantly.

It can also be concluded that by knowing the implementation timings are delayed, a better solution can be found by bringing forward the investments. So far no direct relationship is found in the extent to which investments have to be brought forward. Therefore in the next chapter, this is done manually.

\section{Application to the Hollandsche IJssel}

\subsection{Problem definition}

The Hollandsche IJssel is a fresh water tidal river in the Netherlands. It is closed on the upstream side while at the downstream side the river is protected by a storm surge barrier. This can be schematized as in figure 5 .

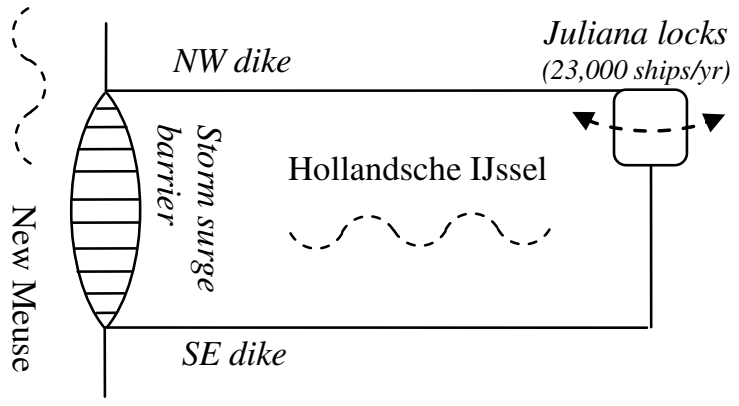

Figure 5. Schematization of the Hollandsche Ijssel

On one side the hinterland is protected by the northwestern dike and on the other side the hinterland is protected by south-eastern dike. $75 \%$ of the dikes have been rejected based upon macro stability $(50 \%$ of NW and $100 \%$ of SE) [3] \& [4]. The dikes subside at a rate of $90 \mathrm{~cm}$ per century due to peat [5]. Upon and along the dikes (especially the SE dike) there is high-density building. Frequently houses are built next to or on top of the dike. This poses problems when reinforcing the dikes, which means costly structural elements have to be applied [6]. This also ensures that reinforcements are possible by a limited amount. Further reinforcing is not desirable as many houses would have to be demolished or moved. For more information see [7].

The storm surge barrier protecting the Hollandsche IJssel dates from 1958 and was constructed as the first part of the Dutch delta works. It is therefore relatively old and has a relatively high non-closure failure probability of approximately 1/75 (e.g. low closure reliability) [8].

It is clear that many problems affect the Hollandsche IJssel. It is therefore necessary to find cost-optimal flood risk reduction strategies. In this chapter, the use of the EAC-method is applied to find these strategies.

\subsection{Interaction with the storm surge barrier}

The non-closure failure probability influences the water levels behind the storm surge barrier. The following equation approximates this interaction:

$$
\begin{gathered}
\text { for } h \geq h_{\text {closure }}: \\
P_{\text {behind }}(h) \approx P_{\text {front }}(h) \cdot P_{\text {fail }, S S B}
\end{gathered}
$$

Where $h$ is the water level, $h_{\text {closure }}$ is the design closure level of the storm surge barrier, $P_{\text {behind }}(h)$ is the annual exceedance probability of a water level behind the storm surge barrier as function of water level, $P_{\text {front }}(h)$ is the exceedance probability of a water level in front of the storm surge barrier as function of water level and $P_{\text {fail,SSB }}$ is the non-closure failure probability of the storm surge barrier.

Suppose for a small numerical example the design closure level $h_{\text {closure }}=3 \mathrm{~m}$ and that this is the water level that occurs on average once every 10 years: $P_{\text {front }}(h)=1 / 10$. Suppose the storm surge barrier fails on 
average every 100 times it closes: $P_{\text {fail,SSB }}=1 / 100$. This means that on average the storm surge barrier is expected to fail to close once every 1000 years, in other words: $P_{\text {front }}(h) \cdot P_{\text {fail, SSB }}=1 / 10 \cdot 1 / 100=1 / 1000$. According to equation (36), this is then also the annual exceedance probability for the water level directly above the design closure level. This interaction is displayed in figure 6.

\section{Water levels with and without SSB}

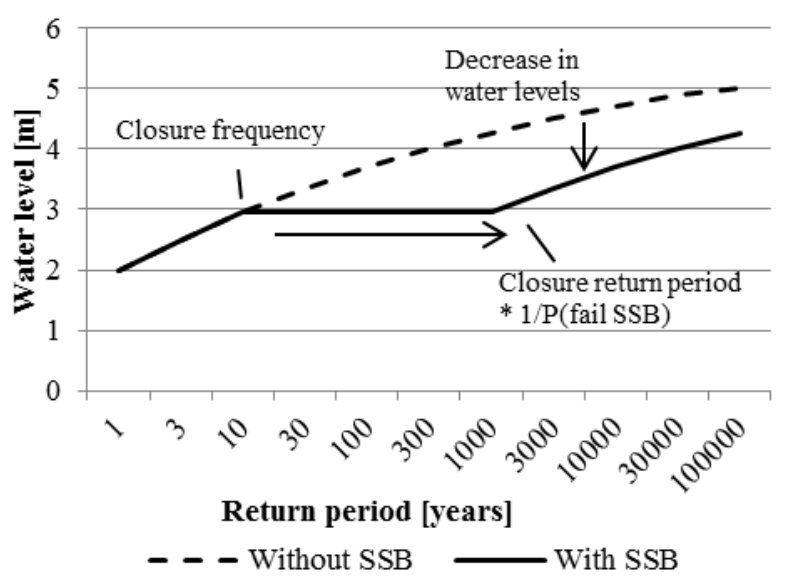

Figure 6. Influence of storm surge barrier (SSB) on high water levels

\subsection{Schematization using fragility curves}

To accurately schematize the Hollandsche IJssel, the river was split up into 7 different representative crosssections (4 for dike ring 14 and 3 for dike ring 15) based upon geometry and consequences of a flood. For these cross-sections, the flood risk was determined by combining so-called fragility curves with the probability density function (PDF) of the water levels and the consequences of a flood (acquired from several assessment reports).

Fragility curves are curves that display the probability of a flood given a certain water level. Hence, they represent the conditional reliability of the dike, as is displayed in figure 7. The PDF of the water levels is determined by deriving the annual exceedance probabilities for water levels, taking into account the interaction with the storm surge barrier as displayed in figure 6. For the Hollandsche IJssel, the annual exceedance probabilities could be determined by using the Hydra-BS software package [9].

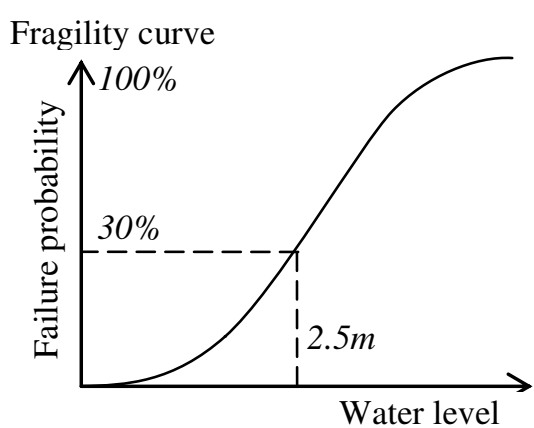

Figure 7. Conceptual example of fragility curve

Equation (37) \& (38) denote how the fragility curves, water levels and the consequences of a flood are combined to determine the annual flood probability $P_{f}$ and annual flood risk $R_{f}$, as was found in [7] \& [10].

$$
\begin{gathered}
P_{f}=\int_{-\infty}^{\infty} f_{s}(h) \cdot F_{R}(h) d h \\
R_{f}=\int_{-\infty}^{\infty} f_{s}(h) \cdot F_{R}(h) \cdot D(h) d h
\end{gathered}
$$

Where $f_{s}(h)$ represents the PDF of the water levels, $F_{R}(h)$ the fragility curve and $D(h)$ the consequences of a flood as function of the water levels.

Fragility curves were created for the two most important failure mechanisms [3] \& [4]: overtopping and macro-stability. For more information on the created fragility curves, see [7]. A short summary is elaborated in this section.

For macro-stability fragility curves the assessment reports proved to provide insufficient information. The phreatic lines in the dike proved to be rather insensitive to changes in the outside water level. This means that if the outside water level changes then the macro-stability safety factor is affected very little. This then means that if the dikes have been rejected for high water levels, they would also be rejected under every day tidal high water levels. This shows the complexity of dikes on peat, though it is clear there is a large stability problem along the Hollandsche IJssel. There is currently ongoing research to this phenomenon [11] \& [12] which proved not to be available yet for this research.

Hence, fragility curves were created upon proven strength using the highest historical water level during the floods 1953. During the floods the dikes breached because of overtopping and not instability. As displayed in figure 8 , assumed is that for water levels lower than the water level of 1953 (corrected for subsidence), the breach probability is zero. For water levels higher than the 1953 water level until the crest height, the breach probabilities are based upon the assessment reports (for lack of better information). For water levels higher than the crest height, the dominant failure mechanism is overtopping which means the breach probability due to macrostability is zero. 


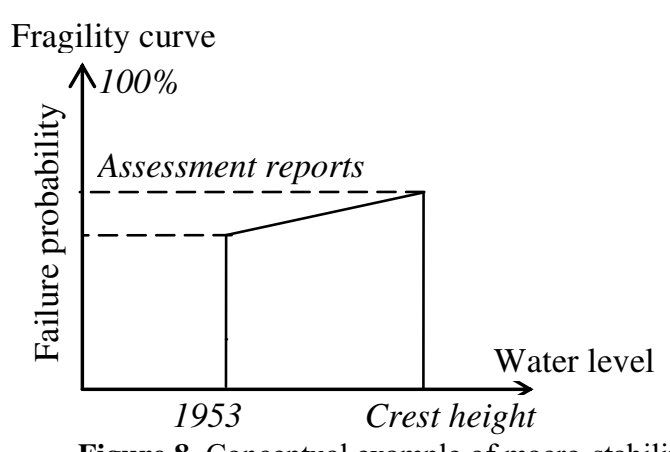

Figure 8. Conceptual example of macro-stability fragility curve for the Hollandsche IJssel

Fragility curves for overtopping were created by determining an average weighted significant wave height for stormy conditions. This eliminates the variable of wind and can only be done because it is a river and the fetch is sufficiently small (not true for lakes or seas). This wave height is assumed to be constant for any water level. This way, for every water level an average weighted overtopping discharge could be determined. Each overtopping discharge (with corresponding water level) was then linked to a breach probability. As no literature for this was available, educated guesses were made what overtopping discharge would lead to what breach probability (see figure 9 ).

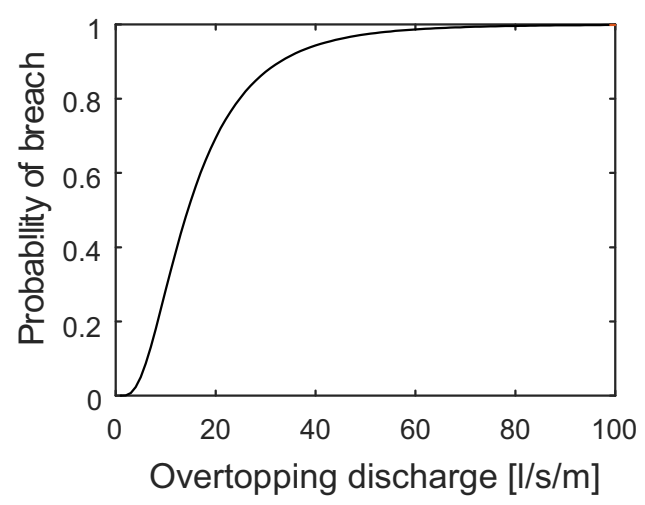

Figure 9. Probability of a breach as function of overtopping discharge used for the Hollandsche IJssel.

\subsection{Reducing flood risk}

The flood risk can be reduced by improving the storm surge barrier (improving the non-closure reliability which influences the PDF of water levels) and/or reinforcing the dikes (affecting the fragility curves).

Minimizing the PV of investments and risk was not an option, because the amounts of combinations are too high. For 6 out of 7 different cross-sections, two dike reinforcement measures were available. The first consists mostly of implementing the costly structural elements improving the stability (while also somewhat increasing the height). The second consists mostly of increasing the height which can only be done after implementing the structural elements. For the $7^{\text {th }}$ cross-section only one possibility was available because the strength of the dike is currently sufficient. For the storm surge barrier 7 possible measures were defined. These are displayed in table 7 .

\begin{tabular}{|l|l|}
\hline No & Description \\
\hline $1 \& 2$ & $\begin{array}{l}\text { Improve } P_{\text {fail,SSB }} \text { to } 1 / 200 \text { and } 1 / 500 \text { for the } \\
\text { current storm surge barrier (end-of-life in 2058) }\end{array}$ \\
\hline 3 & Construct new barrier: $P_{\text {fail,SSB }}=1 / 1000$ \\
\hline 4 & Construct two barriers in a row: $P_{\text {fail,SSB }}=1 / 10,000$ \\
\hline 5 & $\begin{array}{l}\text { Decrease design closure level (only viable if non- } \\
\text { closure failure probability is sufficiently low) }\end{array}$ \\
\hline 6 & $\begin{array}{l}\text { Construct dam with heave pipes that can be } \\
\text { closed, reducing } P_{\text {fail,SSB }} \text { to } 1 / 100,000\end{array}$ \\
\hline 7 & $\begin{array}{l}\text { Construct a dam with breach probability of } \\
1 / 100,000 \text { and close of Hollandsche IJssel and } \\
\text { control inside water level. }\end{array}$ \\
\hline
\end{tabular}

Table 7. Storm surge barrier measures

Costs for constructing the dam are uncertain. It is estimated that it would cost $350 \mathrm{M} €$ excluding dike reinforcing if necessary or $400 \mathrm{M} €$ including dike reinforcing if necessary. Both these figures however exclude nature compensation required by European law [13] which could cost anything between 10 - $1000 \mathrm{M€}$. Costs for nature compensation are unknown and therefore are not taken into account; these would have to be added in the end. During the computation however, they were added as well to take into account the uncertainty associated with this. This led to more diversity in the outcome.

Applying equation (6) proves that initially there are 11,664 combinations of measures possible with the current schematization, only for the first year. Taking into account all years that measures could be implemented would lead to billions and billions of possible flood risk reduction strategies, as equation (4) would also suggest. Therefore, the use of EAC is applied, which would only leave the 11,664 combinations that can be applied at any moment.

Because safety standards are used, the minimal EAC for any combination of measures is only determined when the flood probability exceeds the safety standards. Because using EAC suggests delayed implementation timings, manual post-processing was required to remove several illogical combinations of measures (such as replacing the storm surge barrier two times within 20 years). By altering the discount rate, different flood risk reduction strategies could be found which proved to be economically about equally viable.

\subsection{Results and conclusions}

The result of the research is that out of the many combinations, three different flood risk reduction strategies are defined, which are elaborated below. Costs of the three strategies can be found in table 8 .

The first strategy is to gradually reinforce all dikes and maximize the utilization of the current storm surge barrier. By the year 2058, the storm surge barrier is 100 years and its technical lifetime is exceeded. It then is 
replaced by a new similar storm surge barrier. In the year 2118 however (with the current schematization), dike reinforcements are no longer a possibility (see section 4.1) and canalization of the Hollandsche IJssel becomes inevitable in these simulations. Because this strategy consists mostly of dike reinforcements, this strategy is called the dike reinforcement strategy. The question is however whether or not reinforcing the dikes and increasing the height by approximately one meter is desirable at all? This question is especially valid in the old town centers along the dikes. As the picture in figure 10 will demonstrate, there will be a large societal cost for the local residents. This strategy is closest to the current strategy. The difference is that implementation timings of dike reinforcements are optimized which has led to a present value reduction of approximately $50 \mathrm{M} €$.

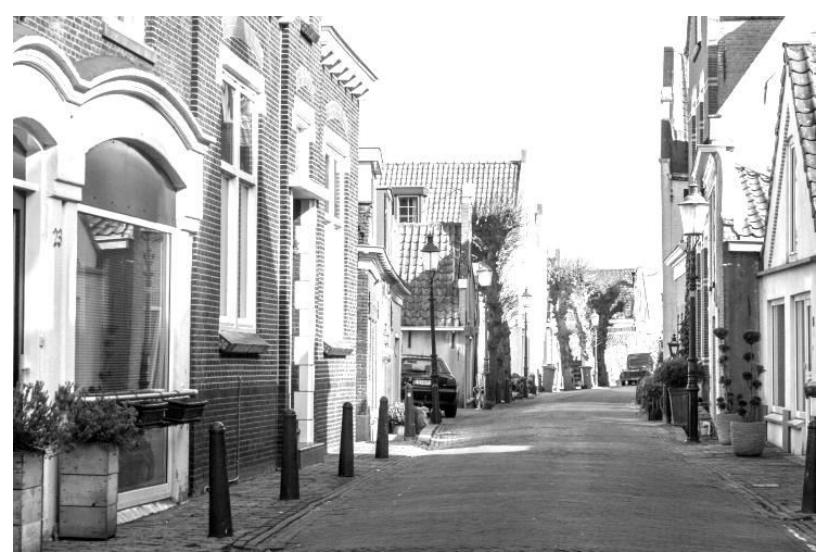

Figure 10. Are dike reinforcements and heightening desirable in old town centers?

The second strategy is to construct two independent storm surge barriers in a row, drastically increasing the closure reliability. However, because of expected subsidence eventually dike reinforcements are still required around the year 2060. Because the closure reliability is sufficiently large, the closure level of the storm surge barrier can be decreased. Ongoing sea level rise ensures that by the year 2100 the closure frequency increases to twice per day during tidal high water. Also because of subsidence, around the year 2126 the flood probability will exceed the safety standards again and dike reinforcements are no longer a possibility (see section 4.1). This means canalization is the only viable solution at that moment in time, just as with the reinforcement strategy. Because the double storm surge barrier, this strategy is called the double barrier strategy.

The third strategy is applying canalization immediately. This strategy avoids most (perhaps undesirable, see figure 10) dike reinforcements and limits them to only those sections that are most unstable. If the controlled water level is equal to the water level behind the Juliana locks (see figure 5), the Juliana locks can be kept open permanently. This means that most ships still only have to pass through a lock once, which means most shipping delays are averted. Only ships with the Hollandsche IJssel as their final destination will experience shipping delay. However, this is likely a minority. The only main downside is the environment. As long as nature compensation costs less than $180 \mathrm{M€}$, immediate canalization is the most economical flood risk reduction strategy. This strategy is therefore called the canalization strategy.

\begin{tabular}{|c|c|c|c|}
\hline & \multicolumn{3}{|c|}{$\begin{array}{l}\text { Present value with discount } \\
\text { rate of } 2.5 \% \text { [M€] }\end{array}$} \\
\hline Strategy & Investments & Risk & Total \\
\hline Dike reinforcement & 552 & 85 & 637 \\
\hline Double barrier & 594 & 57 & 651 \\
\hline Canalization & 400 & 80 & 480 \\
\hline
\end{tabular}

Table 8. Costs for the three flood risk reduction strategies

Optimizations without taking into account safety standards support the proposed safety standards and the impacts of the three main flood risk reduction strategies.

Other strategies that may have seemed viable up front proved not to be viable. For instance: in 2058 the storm surge barrier is 100 years old and is planned to be replaced. Replacing it by a dam at that moment in time seems like the most logical thing to do. However, dike reinforcing requires the implementation of many costly structural elements. These measures have to be applied before 2058 to ensure the dikes will be stable enough and that there will be no height deficit. After implementation of these costly structural elements, it is relatively cheap to improve the height of the dikes if necessary. This means that it is economically more viable to improve the height of the dikes once the structural elements are implemented and replace the storm surge barrier with a newer version than it is to construct a dam.

The only downside of the canalization strategy seems to be the negative impact on nature and as a consequence the uncertainty in nature compensation. Most shipping delays can be avoided by controlling the water level at the same level as behind the Juliana locks (see figure 5) and permanently open these locks. The intrusive dike reinforcements that are perhaps unwanted are also avoided (see figure 10). Canalization eventually is inevitable if chosen not to be implemented immediately. In the current schematization this is around the year 2120. This could differ several years depending on the amount of space that is available to reinforce dikes. However, further reinforcements are not desirable because then many houses have to be demolished or moved to increase the amount of space necessary for further reinforcing. Because of all these arguments mentioned, immediate canalization is the recommended strategy from a flood risk point of view.

\section{Conclusions and recommendations}

The equivalent annual cost expresses all (combinations of) measures in an annual expenditure. This ensures that the EAC is a good way to compare (combinations) of measures that have different economical lifespans with each other.

The use of the EAC method seems to give a fair idea of the general direction in which the cost-optimal flood risk reduction strategy will lead. This means it can be 
used to acquire flood risk reduction strategies that are almost cost-optimal. These can be further optimized to result in cost-optimal strategies. Currently this is done manually, however this can be automated.

The use of equivalent annual cost also assumes that for flood risk reduction, every aspect can be expressed in monetary terms. In practice, other aspects where this cannot be done will also play a role, like for example the nature impacts of canalization.

So far however, the use of equivalent annual cost has only been tested in few situations. Therefore, we recommend applying this method in other cases. We recommend also comparing with minimizing the $\mathrm{PV}$ and the use of EAC in other more complex situations.

The model proposed as so far also does not take into account uncertainties. Every input is assumed to be a certainty. By means of a sensitivity analysis however, the results of the three strategies for the Hollandsche IJssel seem to be robust with a variety of assumptions. It is recommended to further implement uncertainty.

It is interesting to expand the mount of dependent combinations of measures in section 1.3 equation (6) with all possible implementation timings to determine the amount of flood risk reduction strategies with dependent measures, as is also done in section 1.2 with independent measures.

Finally, it is interesting to find analytical solutions to the problem in section 3.2.2 if they appear to exist. That would result in a better comparison between the EAC method and minimizing present values for the simplified situations as described in section 3.2.

\section{References}

1. Brealey, R.A. and S.C. Myers, Principles of Corporate Finance. 9th edition ed, ed. F. Allen. 2007: McGraw Hill Education.

2. Jones, T.W. and J.D. Smith, An Historical Perspective of Net Present Value and Equivalent Annual Cost. Accounting Historians Journal, 1982. 9(1).

3. Hoven, I.A.v. and I.P. Kraaijenbrink, Assessment reports primary flood defence Schieland (New Meuse \& Hollandsche IJssel). 2003, GeoDelft commissioned by the regional water authority of Schieland \& Krimpenerwaard.

4. Sjenitzer, S.L. and H. Larsen, Assessment reports dike ring 15. 2004, GeoDelft commissioned by the regional water authority of Schieland \& Krimpenerwaard.

5. Van der Kraan, A., Subsidence maps (concept). 2012.

6. RHDHV, Kwalificeren Dijkversterking Hollandsche IJssel voor NHWBP Nederland, A.J.v.d. Kerk, Editor. 2012.

7. Schoemaker, M.A., Flood Risk Assessment \& Investment Framework: A framework for flood risk reduction strategies in the Hollandsche IJssel. 2016, Delft University of Technology. p. 282.
8. Rijkswaterstaat, Newsletter storm surge barriers (nieuwsbrief stormvloedkeringen) - july 2015. 2015.

9. Duits, M.T., Hydra-B for HR2006 - User manual version 3.5. 2007, HKV Lijn in Water.

10. van der Meer, J.W., W.L.A. ter Horst, and E.H. van Velzen, Calculation of fragility curves for flood defence assets. Flood Risk Management: Research and Practice, 2008.

11. Project KIJK, Soil survey for dike reinforcements of Krimpenerwaard dikes. 2015, Regional water authority of Schieland \& Krimpenerwaard.

12. POV Macrostabiliteit, Cross-project exploration macro-stability. 2015, High Water Protection Program: Regional water authority of Rivierenland.

13. European Commission, Habitats Directive - article 6(4) (management of natura 2000 sites compensatory measures). 1992. 